\title{
Research on Ecological Tourism Development of North Slope of Changbai Mountain
}

\author{
Mingju Liu \\ Yatai School of Business Administration \\ Jilin University of Finance and Economics \\ Changchun, Jilin, China 30117
}

\author{
Liguang Zhao \\ School of Taxation \\ Jilin University of Finance and Economics \\ Changchun, Jilin, China 130117
}

\author{
Xinyue Zhang \\ Yatai School of Business Administration \\ Jilin University of Finance and Economics \\ Changchun, Jilin, China 130117
}

\begin{abstract}
In our country, the development of ecological tourism has showed overwhelming tendency. Ecological tourism not only ensures the maximization of resource utilization rate, but also promotes harmonious development of economy and environment. Changbai Mountain is renowned as one of the famous scenic spot of our country. Provincial government and local management personnel attach great importance to the development of its ecological tourism. This article focuses on researching some problems existed in development of ecological tourism of North Slope of Changbai Mountain and puts forward feasible solutions to promote development of local economy and realize sustainable development of ecological environment of North Slope of Changbai Mountain.
\end{abstract}

Keywords-North Slope of Changbai Mountain; ecological tourism; sustainable development

\section{INTRODUCTION}

With rapid development of economy, nowadays, tourism industry has become the fastest growing industrial sector in the world and developed into pillar industry in China. As one of the important branches of tourism, tourism industry is popular among people. They begin to use spare time to return to nature, pursue zero distance contact with nature, but when driving rapid development of economy, they cause different degrees of damage. It is in urgent need of us to deal with relationship between tourism economy and ecological environment and realize harmonious development between them.

\section{RESEARCH PROGRESS OF ECOLOGICAL TOURISM}

\section{A. Research Progress in Foreign Countries}

The concept of ecological tourism was first put forward in 1983 by Ceballas Laskurain, special advisor of IUKN. It causes great repercussion around the world. The academic circles begin to energetically research ecological tourism, which becomes the key point for scholars to research and pay attention to. In 1988, Ceballas Laskurain defined ecological

Fund program: National Natural Science Foundation of China (project number: 414101146); science and technology development project in Jilin province $(201502040 \mathrm{NY})$. tourism as "a kind of tourist activity as well as special form of routine tourism learning in natural region free from contamination and appreciating beautiful scenery and wild animals and plants". In 1996, King thought ecological tourism refers to tourism behavior carried out in natural region, aiming at appreciating and enjoying natural landscape without damaging ecological environment. It is observed that the research on ecological tourism focuses on two key points at initial stage. On one hand, ecological tourism is carried out in region with good natural environment; one the other hand the implementation of ecological tourism will not damage the environment.

With in-depth research on ecological tourism, it has become an important way to realize sustainable development of tourism and realize harmony and unity of human and nature. In Europe and America with developed economy, people would like to keep away from noisy city and return to nature, so ecological tourism develops rapidly. In development and protection of ecological tourism, some developed countries such as Japan, Europe and America always take the leading position, which provides valuable experience for other developmental countries to carry out related researches.

\section{B. Related Researches in Our Country}

Compared with other countries that have developed ecological tourism and tourism industry, our country has a late start and mainly depends on national forest parks to develop. In 1982, the first national forest park of our country, the Zhangjiajie National Forest Park was established. It organically integrates tourism development with protection of ecological tourism environment and lays foundation for development of follow-up ecological tourism. In 1994, "CETA" was established, which was an important milestone in tourism development of China. With deepening of research, domestic scholars begin to pay attention to researching characteristics, development principles and certification system of ecological tourism and apply sustainable development to ecological tourism. In recent years, scholars 
begin to transfer the emphasis of research to research method and research mode and carry out empirical research by taking individual tourist attractions as cases to realize sustainable development of tourism industry of our country.

\section{CurRent Situation OF DeVElopment of ECOLOGICAL TOURISM IN NORTH SLOPE OF CHANGBAI MOUNTAIN}

\section{A. Natural Conditions for Changbai Mountain to Develop Ecological Tourism}

Changbai Mountain Scenic Area is located in southeastern of Jilin and belongs to 5A grade scene spot. Changbai Mountain is renowned as one of the ten famous mountains of our country and gets its name because the main peak accumulates snow throughout the year. Changbai Mountain belongs to typical volcanic landform. The altitude difference in the scenic spot is near to 2000 meters. The landform is mountain landscape. The climate feature is: Winter is long and piercingly cold; summer is short and warm cool; spring is windy and dry; autumn is foggy and cool. Most of the time, the air temperature in Changbai Mountain Scenic Spot is lower than that of other regions in Jilin province. In winter, it often has heavy snowfall, so they will seal the mountain pass from December in winter to March in the next year. Famous scenic spots in Changbai Mountain Scenic Area have Tianchi, Changbai Waterfall, Julong Hot Spring and Luyuantan Pool, with unique charm of their own, forming colorful scenery in Changbai Mountain Scenic Area.

\section{B. Situation of Tourists' Reception in North Slope of Changbai Mountain}

Under normal circumstances, Changbai Mountain Scenic Area receives more than ten thousand of tourists every day. In peak season of tourism such as National Day and May Day, it often receives more than twenty thousand of tourists every day. When the number of tourists reaches twenty-four thousand, the scenic area will stop selling the tickets to prevent the situation that tourists in the scenic area are too crowded. It is also the biggest bearing value of Changbai Mountain Scenic Area. But in tourist off-season or under the circumstance that the climate is extremely cold, the number of tourists in the scenic area reduces sharply. Sometimes when it meets rainstorm or heavy fog, the scenic area will seal the mountain pass. The number of tourists will create the minimum value of a year. The fluctuation and difference of number of tourists in Changbai Mountain Scenic Area have great instability.

\section{Current Situation of Infrastructure Construction in North Slope of Changbai Mountain}

Infrastructure in the scenic area includes dustbin, toilet, guard bar, indicator, ticket office and management office in the scenic area. They often play an important role in visiting process of tourists. The number of toilets in North Slope of Changbai Mountain isn't sufficient. The toilet in Changbai Waterfall is closed in four or five o'clock in the afternoon. It often appears the situation that when some tourists are informed that the toilet cannot be used after they go to the waterfall. When there are too many tourists, in tourist rest center, it often has the phenomenon that tourists queue up to go to the bathroom. It spends a long time and makes tourists dissatisfied.

\section{PROBlEMS EXISTING IN ECOLOGICAL TOURISM OF NORTH SLOPE OF CHANGBAI MOUNTAIN}

\section{A. Infrastructure is Unsound, Lacking in Consideration for Details}

At present, infrastructure designed for tourists in Changbai Mountain Scenic Area is unsound. Facilities providing convenience for tourists are still in hysteretic state. Infrastructure is the key part in scenic area to receive tourists and shall attract high attention of administrators in scenic area.

1) The quantity is not sufficient.: The number of facilities offered for tourists to have a rest in scenic spot is limited. Changbai Mountain Scenic Area receives tens of thousands of tourists every day in average, including the aged and children. But when climbing more than two hundred steps from Julong Hot Spring to Changbai Waterfall, most tourists feel tired; especially the aged and parents carrying babies need to have a rest. So some tourists choose to directly sit on the ground of open-air square or stones beside the water. It will not benefit the health and safety of tourists and the development of landscape in Changbai Mountain Scenic Area.

On the other hand, the climate in Changbai Mountain is changeable and it often rains. But there are few facilities for tourists to take shelter from rain in the scenic area. There isn't any shelter above the bench. Heavy rain often makes tourists unprepared. The scenic area doesn't take the health of tourists into adequate consideration. There aren't enough dustbins in the scenic area, which lead to the situation that some tourists cannot find dustbins, so they throw waste on the ground and destroy the natural environment.

2) There exist security issues: The scenic area shall set up safety facilities to guarantee tourists' safety and let them put their heart and soul into visiting without burden and concerns. Safety facilities in Changbai Mountain Scenic Area also have security issues. They mainly use long rope to serve as shield at the rim of square for tourist to enjoy the sight of waterfall. Because it is not replaced for a long time, the rope becomes loose and hangs down. Tourists can step across easily. Many tourists step across the long rope, climb on the rock bank with height of two meters and collect water at torrential downstream of the waterfall. It is very easy for them to slip into the ice-cold and torrential water and have life danger. They use wooden fence between the waterfall and square to protect the tourists. But some tourists are easily to move the fence and enter the forbidden area to take photos. Because rockfall often fall from the mountain and may hit people, this behavior of tourists is also very dangerous.

\section{B. Personnel Allocation Cannot Meet Increasing Requirements of Tourists}

Workers in the scenic area play the roles of guiding tourists, providing consultations, protecting environment and making 
emergency treatment. It requires sufficient number of personnel as well as quality and ability of person in charge. The Changbai Mountain Scenic Area has extensive area. Workers in the scenic area are responsible for many things. So it requires reasonable personnel allocation. If the climate changes or emergency happens, they need to immediately send more people to help. The manpower is obviously insufficient. There are many foreign tourists who come here to enjoy the sight of Changbai Mountain. But the staff cannot speak simple foreign spoken language. It is impossible for them to make simple communication with foreign friends and make correct response to problems asked by them. There aren't special management and consulting department of tourists in the scenic area.

\section{The Development Is Backward and Economic Benefit Is Not Significant}

The number of tourists in North Slope of Changbai Mountain has increasing tendency every year, but the scenic area does not improve greatly. Almost all local economic development relies on the income of admission ticket of Changbai Mountain Scenic Area. Some featured products in Changbai Mountain are also small brands with small scale. Changbai Mountain has abundant resources. The local production has advantaged quality advantage. It should have vast potential for future development on market. But special local products in Changbai Mountain such as Tianchi water, ginseng and wood frog don't have well-known brands. In addition, in peak season of tourism in every year, the income of Changbai Mountain Scenic Area is lower than that of famous scenic areas such as Mount Huang and Mount Tai. Although the income of Changbai Mountain Scenic Area can keep up with average income of scenic areas of our country, the incomes in peak season and slack season of tourism are obviously different.

\section{COUNTERMEASURES FOR NORTH SLOPE OF CHANGBAI MOUNTAIN TO DEVELOP ECOLOGICAL TOURISM}

\section{A. Adhere to Taking the Development of Ecological Tourism as Objective}

The development of Changbai Mountain Scenic Area adheres to taking the development of ecological tourism as the fundamental objective. Develop economy under the premise of not destroying the environment, change Changbai Mountain from simple tourism scenic area to compound scenic area of ecological tourism, integrate more new type elements into traditional development pattern of the scenic area, meanwhile, pay attention to protecting the environment, reduce pollution and wastage of vegetation. Reasonably develop resources in Changbai Mountain, promote local products and brands to broader and further markets, improve international popularity, and forge Changbai Mountain into the world first class and famous destination for travel, leisure and holiday.

\section{B. Increase Capital Investment and Improve Infrastructure Contruction}

Local government need to allocate funds to construct sound infrastructure and provide convenience for tourists. Perfect infrastructure will also bring new look of the scenic area, which can make tourists feel pleasure. When constructing perfect infrastructure, it is necessary to learn to change roles, consider the details from the perspective of tourists and put the feelings of tourists in the first place. Increase more facilities and places for tourists to have a rest in the scenic area. For scenic spots in open air, they shall consider different weather conditions to provide facilities for tourists to take shelter from rain or sun. For toilets in each scenic spot, they shall also consider the requirements of tourists and prolong opening hours to the greatest extent. In consideration of safety of tourists, they need to regularly replace shield and handrails, lift the shield to the place that is difficult for tourists to step across, tie up iron chains between handrails and ensure there isn't gap, increase more warning signs to remind tourists to watch out.

\section{Strengthen Construction of Scenic Area, Further Develop Resources}

Because ecological environment is very vulnerable, when developing and constructing, we should put the protection of ecological environment in the first place all the time. It is not suitable to build largely in the scenic area and create the original look and realize planning target through destroying the vegetation. We should adjust measures to local conditions and perfectly integrate construction of scenic area with nature. The scenic area shall further develop resources and create unique brands of Changbai Mountain. Increase publicity and create economic benefit. For example, for the original pollution free underground mineral water in Changbai Mountain, we can pay attention to publicizing purity of water quality and rich minerals, enlarge scales to produce in local area, avoid unnecessary loss and consumption caused by internal competition, implement unified management of other small businesses, and finally unify them into a brand to enlarge the scale and improve market shares. There are many other resources remained to be developed in Changbai Mountain, such as planting of drugs and domestication of animals. If we can reasonably develop and use, it will bring immeasurable benefits for Changbai Mountain Scenic Area and local economy.

\section{Intensify Training of Employed Person, Innovate Management System}

1) Increase number of staff: The North Slope of Changbai Mountain has vast area and many scenic spots. It needs perfect management system and sufficient manpower resources. They need to arrange one or two people to deal with sudden changes of weather and emergencies. They need to set a tourist management center in each scenic spot, responsible for arranging work for staff and reporting to and asking for instructions of the next higher management level. It can realize level-to-level administration, which can avoid the situation of notification bypassing the immediate leadership as well as timely find problems then control and allocate.

2) Improve the quality of staff: Staff of high quality can not only add beautiful scenery to the scenic area but also help the implementation of work in Changbai Mountain Scenic Area. Talents are also the key to develop tourism, so we need 
to employ talents of high quality to train and manage, arrange suitable posts for them according to their characteristics and abilities. Staff members in the scenic area must be patient, enthusiastic and persevering. They shall be able to bear difficult environment on the mountain, face visitors with smile all the time, and have good psychological quality. It is better for them to have certain educational level. When answering questions of visitors, they shall pay attention to tone and choice of words to make tourists satisfied and moved. The Changbai Mountain Scenic Area is famous scenic area of our country and attracts many foreign friends. Staff members shall also be able to speak some foreign languages and can take it easy in face of various tourists under any circumstances. If they cannot understand what foreign tourists say, they cannot be irritable but patiently communicate with these visitors and ask for help. They shall provide one young commentator in each scenic spot to use skillful foreign language and mandarin to simply introduce relevant knowledge of the scenic spot to tourists and answer questions of tourists. It is necessary to evaluate the work of employees in each scenic spot regularly, adjust personnel allocation and improve management system of the scenic area. It can not only stimulate enthusiasm of staff members but also find and correct problems.

\section{E. Enrich Cultural Connotation of the Scenic Area, Improve Attraction of Tourism}

In history, Changbai Mountain was the place for people in northeast China to work and also the birthplace of Manchu culture, having good reputation of "Holy Land". Changbai Mountain has a long history. Because the peak of it has accumulated snow all the year round, it is the symbol of purity and holiness. Except for rich cultural deposits, there are many mysterious legends in Changbai Mountain. The Lake Tianchi Monster is the most famous. In all ages, people have witnessed the existence of it for thirteen times, which also add a mysterious veil to Changbai Mountain. There is no lack of tourists who visit Changbai Mountain because of the legend of Lake Tianchi Monster. There are also many tourists who visit here with sacred beliefs. We can integrate these unique cultures into tourism to form some characteristic cultural forms, such as providing tourists with tourism of Manchu culture and tourism of legends of Changbai Mountain. What's more, we can develop products and services according to culture of Changbai Mountain, such as provide dolls of Lake Tianchi Monster, establish brands, and offer special places and facilities for tourists who pilgrimage and show respect for their beliefs. The service can meet curiosity of tourists and make tourists who pilgrimage have a good impression, attract tourists at different stratums but hoping to feel the culture of Changbai Mountain. Besides, in surrounding areas of Changbai Mountain, they can hold large-scale campfire party and show songs and dance with Korean characteristics, which can not only publicize distinctive culture, but also stimulate economic growth of local places to bring in income for residents in surrounding areas.

\section{CONCLUSION}

The development of ecological tourism of North Slope of Changbai Mountain shall carry out construction concept of sustainable development all the time, pay attention to the protection of ecological environment and strengthen propaganda effect. It shall increase popularity in Chinese market as well as become international famous scenic spot to attract people to visit scenery in Changbai Mountain. As a new type of way for traveling, ecological tourism has large development space. It lets us experience the original scenery and feel green plants in natural environment, relax our mind, cultivate our taste and then realize the importance to conservation of nature and ecology.

\section{REFERENCES}

[1] Cao Guangcheng. Countermeasures of Ecological Tourism Development of Changbai Mountain [M], Beijing: Electronic Industry Press, 2008.

[2] Walter Christaller.Some considerations of tourism location in Europe:The peripheral regions-under-developed countries-recreation areas[N].Papers of the Regional Science Association,1964.

[3] Blair H.Sheppard ,Roy J.Lewicki.Toward general principles of managerial fairness[J].Social Justice Research,1987.

[4] Glenn R .Matlack.Sociological edge effects:Spatial distribution of human impact in suburban forest fragments[J].Environmental Management, 1993.

[5] Mathis Wackernagel,J.David Yount.Footprints for Sustainability: The Next Steps[M].Environment,Development and Sustainability,2000.

[6] Miao Zhengfang. Summary of Regional Tourism Environment Research in Our Country [D], Geography and Geo-Information Science, 2004.

[7] Liu Mingjue. Research on Sustainable Development of North Slope of Changbai Mountain [J], Taxation and Economy, 2015.

[8] Ma Congling. From Concept to Demonstration: Future of Chinese Tourism Research [J], Tourism Tribune, 2007

[9] Wang Chunmei. Discussion on How to Scientifically Deal with Relationship between Environmental Protection and Tourism Development [J], Journals of Tourism Science, 2014. 